\title{
RESEARCH
}

Open Access

\section{Increased incidence of precocious and accelerated puberty in females during and after the Italian lockdown for the coronavirus 2019 (COVID-19) pandemic}

Stefano Stagi ${ }^{1 *}$ D, Salvatore De Masi ${ }^{2}$, Erica Bencini², Stefania Losi ${ }^{2}$, Silvia Paci ${ }^{2}$, Maria Parpagnoli², Franco Ricci ${ }^{2}$, Daniele Ciofi ${ }^{2}$ and Chiara Azzari ${ }^{1}$

\begin{abstract}
Background: The timing of puberty in girls is occurring at an increasingly early age. While a positive family history is recognised as a predisposing factor for early or precocious puberty, the role of environmental factors is not fully understood.

Aims of the study: To make a retrospective evaluation of the incidence of newly diagnosed central precocious puberty (CPP) and the rate of pubertal progression in previously diagnosed patients during and after the Italian lockdown for COVID-19, comparing data with corresponding data from the previous 5 years. To determine whether body mass index (BMI) and the use of electronic devices increased during lockdown in these patients.

Patients and methods: The study included 49 females with CPP. We divided the patients into two groups: group 1, patients presenting a newly diagnosed CPP and group 2, patients with previously diagnosed slow progression CPP whose pubertal progression accelerated during or after lockdown. We collected auxological, clinical, endocrinological and radiological data which were compared with data from two corresponding control groups (patients followed by our Unit, March to July 2015-2019). Patients' families completed a questionnaire to assess differences in the use of electronic devices before and during lockdown.

\footnotetext{
* Correspondence: stefano.stagi@yahoo.it

'Health Sciences Department, Anna Meyer Children's University Hospital, University of Florence, Viale Pieraccini 24, 50139 Florence, Italy

Full list of author information is available at the end of the article
}

(c) The Author(s). 2020 Open Access This article is licensed under a Creative Commons Attribution 4.0 International License, which permits use, sharing, adaptation, distribution and reproduction in any medium or format, as long as you give appropriate credit to the original author(s) and the source, provide a link to the Creative Commons licence, and indicate if changes were made. The images or other third party material in this article are included in the article's Creative Commons licence, unless indicated otherwise in a credit line to the material. If material is not included in the article's Creative Commons licence and your intended use is not permitted by statutory regulation or exceeds the permitted use, you will need to obtain permission directly from the copyright holder. To view a copy of this licence, visit http://creativecommons.org/licenses/by/4.0/ The Creative Commons Public Domain Dedication waiver (http://creativecommons.org/publicdomain/zero/1.0/) applies to the data made available in this article, unless otherwise stated in a credit line to the data. 


\begin{abstract}
(Continued from previous page)
Results: Thirty-seven patients presented newly diagnosed CPP (group 1) and 12, with previously diagnosed but untreated slow progression CPP presented an acceleration in the rate of pubertal progression (group 2). The number of new CPP diagnoses was significantly higher than the mean for the same period of the previous 5 years $(p<0.0005)$. There were no significant differences between patients in group 1 and control group 1 regarding time between appearance of B2 and CPP diagnosis, although group 1 patients had a significantly earlier chronological age at B2, a more advanced Tanner stage at diagnosis $(p<0.005)$, higher basal LH and E2 levels, higher LH peak after LHRH test $(p<0.05)$ and increased uterine length $(p<0.005)$ and ovarian volume $(p<0.0005)$. The number of patients with previously diagnosed CPP whose pubertal development accelerated was also statistically higher compared to controls $(p<0.0005)$. In this group, patients' basal LH $(p<0.05)$ and E2 levels $(p<0.0005)$ became more markedly elevated as did the LH peak after LHRH test $(p<0.05)$. These patients also showed a significantly accelerated progression rate as measured by the Tanner scale $(p<0.0005)$, uterine length $(p<0.005)$, and ovarian volume $(p<0.0005)$. In both group 1 and group 2, BMI increased significantly $(p<0.05)$ and patients' families reported an increased use of electronic devices $(p<0.0005)$.

Conclusion: Our data show an increased incidence of newly diagnosed CPP and a faster rate of pubertal progression in patients with a previous diagnosis, during and after lockdown compared to previous years. We hypothesize that triggering environmental factors, such as the BMI and the use of electronic devices, were enhanced during lockdown, stressing their possible role in triggering/influencing puberty and its progression. However, more studies are needed to determine which factors were involved and how they interacted.
\end{abstract}

Keywords: Precocious puberty, Accelerated puberty, COVID-19

\section{Introduction}

Puberty is the result of a complex neuroendocrine system, initiated by an unknown primary mechanism, and characterized by the increased release of gonadotropinreleasing hormone $(\mathrm{GnRH})$ by the hypothalamus $[1,2]$. The phenomenon is related to a complex sequence of endocrine changes and is influenced by integrated multiple peripheral and central signals leading to the development of sex characteristics, the growth spurt and the obtaining of reproductive competence $[1,2]$.

Currently, abnormally precocious sexual development (precocious puberty or PP) is defined as the occurrence of Tanner stage B2 before 8 years in girls and Tanner stage G2 before 9 years in boys. The average age of onset of puberty has decreased over the last century [3-5]. Historical data from Europe show a sharp decline in mean age at menarche from approximately 17 years in the early nineteenth century to approximately 13 years by the mid-twentieth century, with a minor decrement during the past 25-30 years [5]. Mean age at onset of breast development has also decreased in all ethnic groups [6], as reported by the Pediatric Research in Office Settings (PROS) study [3] and the data by Biro et al. [7]. These same data show a progressive increase in the number of girls fulfilling the criteria for PP $(6.7 \%$ in the PROS study and $10.4 \%$ in the Biro data for white girls) $[6,7]$.

Genetic factors undoubtedly play a major role in these trends [8]. However, there is a consensus that environmental variables, such as weight, foetal nutrition, childhood dietary habits, physical activity, psychological factors, and exposure to electromagnetic fields (EMF) and/or endocrine disrupting chemicals, also have an impact $[2,5,9]$.

In Italy, as elsewhere, the COVID-19 pandemic created an unprecedented strain on health care and during the strictest months of lockdown forced millions of people to remain isolated in their homes for about 2 months, from March to May 2020 [10, 11]. It is possible that the lockdown enhanced the impact of factors interfering with the timing and tempo of puberty, such as adiposity $[12,13]$ and psychological wellbeing. An increased incidence of depression, anxiety and stress have been reported to varying degrees in adults [14], and even if comprehensive data among children and adolescents are scarce, it is likely that children had similar psychological reactions.

The aims of this study are to evaluate the frequency of precocious puberty and the rate of pubertal progression in girls during and after the lockdown, comparing results with data for the same period over the last 5 years and to consider possible correlations between lockdown conditions and trends in the data.

\section{Patients and methods}

We retrospectively evaluated the medical records of Caucasian patients referred to the Auxoendocrinology and Paediatric Gynaecology Unit of the Meyer Children's University Hospital for CPP (group 1) during and after the Italian lockdown for the COVID-19 infection (March July 2020), comparing this data with the medical records 
of the same period of the previous 5 years (March-July 2015-2019) (control group 1). We also collected data on the rate of pubertal progression (the tempo of puberty) in patients already followed by our Unit for untreated and slow progressive PP (group 2), again comparing the data with the same period of the previous 5 years (control group 2).

Patients with a diagnosis of CPP and associated hypothalamic-pituitary congenital malformations, neurological, neurosurgical and/or genetic diseases, psychomotor delay, oncological diseases, other endocrine impairments requiring hormonal treatments, or taking drugs that may interfere with pubertal development were excluded from the study. We also excluded children who were adopted or had immigrated to Italy as such children have a statistically higher rate of precocious puberty than the general pediatric population.

The study was performed according to the Helsinki II declaration and approved by the local Paediatric Ethical Committee (approval number: 30/07/2020-179). Written informed consent was obtained from the parents of enrolled children.

\section{Study design}

All patients underwent a physical examination and auxological evaluation. We recorded height, weight, body mass index (BMI), height velocity (HV) and stage and rate of pubertal progression (Tanner scale) [15]. HV was calculated at least once in every year and was defined as the increase in height in centimeters per year [15]. BMI was calculated by dividing the patient's weight in kilograms by the square of height in meters [16]. Height, $\mathrm{HV}$ and BMI were normalized for chronological age by conversion to SD scores [15]. When possible, target height $(\mathrm{TH})$ SD scores were also calculated.

If available, we collected clinical data (e.g. age at CPP diagnosis, personal and family history for major diseases, family history for CPP) and endocrinological data (follicle-stimulating hormone $[\mathrm{FSH}]$, luteinizing hormone [LH], estradiol [E2], dehydroepiandrosterone sulfate [DHEAS], 17-hydroxyprogesterone [17-OHP], prolactin [PRL], free thyroxine [FT4], thyroid-stimulating hormone $[\mathrm{TSH}])$. In addition, a pelvic ultrasonography, a bone age (BA) assessment using radiographs of the left hand and wrist and a LH-releasing hormone (LHRH) stimulation test were performed.

Pubertal development was classified according to the Marshall and Tanner criteria [17]. The age of pubertal onset was defined as the age at durable Tanner B2 stage, confirmed by the auxological, endocrinological and/or radiological results [14]. The rate of pubertal progression was taken to be the time from B2 to B3 and/or B4 [14].

Skeletal maturation was expressed as BA and evaluated, when possible, as the ratio of the change in $\mathrm{BA}$ to the change in chronological age (CA) (BA/CA), and as the difference between $\mathrm{CA}$ and $\mathrm{BA}$ (CA minus $\mathrm{BA}$ ) in years [14].

Precocious puberty was defined as the development of pubertal changes at an age that was younger than the accepted lower limits for age of onset of puberty (before the age of 8 years in girls) [18]. We considered peak LH values of $>5 \mathrm{IU} / \mathrm{L}$ on the $\mathrm{GnRH}$ in the presence of $\mathrm{pu}$ bertal signs or a basal $\mathrm{LH}$ value of $>1.1 \mathrm{IU} / \mathrm{L}$ and a ratio of stimulated LH to stimulated FSH of $>1.0$ combined with isolated and/or axillary hair growth accompanied by breast development [18] to be indicative of activation of the hypothalamic $\mathrm{GnRH}$ pulse generator.

For the purposes of this study, the rate of puberty progression was evaluated:

- for group 1 patients with new CPP diagnoses and control group 1, by the time between the appearance of a durable Tanner stage 2 and diagnosis. For these patients auxological parameters were recorded at diagnosis and compared with those recorded by the patient's paediatrician at the moment of referral.

- for group 2 patients with untreated CPP patients who had presented slow progression prior to lockdown and control group 2, by the progression rate assessed by a Paediatric Endocrinologist (S.S.). All CPP patients are assessed every 3-4 months by our Unit to determine whether the rate of pubertal progression is stable or accelerating. We defined slow or accelerated pubertal development if the rate of progression from one pubertal stage to another is more or less than 6 months or $1 \mathrm{SD}$ in comparison with the general population $[19,20]$.

Moreover, based on our previous data [21], we also evaluated quantitatively and qualitatively changes in the use of electronic devices before and during lockdown in these patients [21]. Parents were asked to complete a questionnaire specifying which devices children used, how long they used them for, at what times of the day and whether they were used by the children in their bedrooms during the hours before they went to sleep. The devices considered were: PCs, cell phones, MP3 players, tablets, game consoles and TVs. Data were collected after the lockdown. Time spent on screen-based activity was assessed by the following question: "including school hours (only during lockdown), how much time do you (the child) usually spend on the following: (1) TV, (2) TV-games (PlayStation, Xbox, WII, etc), (3) PC games, (4) Internet chatting, (5) using the PC for other purposes)?" The response alternatives were: 'no time', 'less than $1 / 2$ hour', ' $1 \frac{1}{2}$ hour to 1 hour', $1 \mathrm{~h}$ to $2 \mathrm{~h}$ ', ' 2 hours to 3 hours', ' 3 hours to 4 hours', ' 4 hours to 5 hours' and 'more than 5 hours'. Most recommendations for screen- 
based activities restrict screen time for children and adolescents to about $2 \mathrm{~h}$ per day [22].

\section{Auxological evaluation}

Height was measured using Harpenden's stadiometer in triplicate to the nearest $0.1 \mathrm{~cm}$. Weight was determined to the nearest $0.1 \mathrm{~kg}$ using a balance scale. Age-related reference values for height, bone age and BMI were those currently used in Italy, obtained in high sample numbers of Italian children, as previously reported [14, 15]. Height, HV, and BMI were normalized for chronological age by conversion to standard deviation (SD) scores according to the following formula: patient value - mean of age-related reference value/standard deviation of the age-related reference value $[14,15]$. BA was evaluated through radiographs of the left hand and wrist and then calculated according to the Greulich and Pyle method [23]. TH was estimated according to the Hermanussen and Cole method [24], calculating mid-parent height as an SD score and correcting this by a factor corresponding to the influence of assortative mating and parent-offspring correlations.

\section{Pelvic ultrasonography}

Pelvic ultrasonography was performed by the same operator (E.B.), using a Siemens Sonoline Elegra sonograph and a $6.5-\mathrm{MHz}$ probe. The surface area $(\mathrm{S})$ of the ovaries was calculated as follows: $\mathrm{S}=$ length $\mathrm{x}$ width $\times 0.8$. The normal ovarian surface area is $<2 \mathrm{~cm}^{2}$ in prepubertal and from 2 to $6 \mathrm{~cm}^{2}$ in pubertal subjects [25].

\section{Laboratory methods}

All laboratory measurements were performed on blood samples collected after overnight fasting. Plasma FSH and LH, PRL, 17OHP, DHEAS, FT4, TSH, and E2 levels were measured by means of chemiluminescent immunometric assays with the use of commercially available kits for the Immulite 2000 systems analyzer (Siemens Healthcare Diagnostics).

The LHRH test was carried out by taking blood samples at the 15th, 30th, 45th and 60th minute after intravenous administration of $100 \mathrm{mg} / \mathrm{m} 2$ (maximum 100 mg) LHRH (Lutrelef, $0.8 \mathrm{mg} / 10 \mathrm{~mL}$; Ferring).

\section{Statistical analysis}

Statistical analyses were performed with the use of SPSS $\mathrm{X}$ software (SPSSX Inc., Chicago, IL, USA). The characteristics of the study population were described using frequency distributions for categorical variables and mean and standard deviation (SD) values, medians, and ranges for continuous variables, depending on whether the data were normally distributed. The statistical significance of the continuous variable comparisons was assessed using the Student $\mathrm{t}$ test and the Mann-Whitney
$\mathrm{U}$ test, depending on the distribution of the analyzed variable; the comparison of categorical variables was conducted using the chi square test or Fisher's Exact test if there was a small $(<5)$ expected cell size. The Pearson correlation test was used to determine the correlation coefficients. All statistical tests were two-tailed and a $p<0.05$ was considered statistically significant.

\section{Results}

Clinical data and laboratory results were analysed in 49 females. All patients showed normal values of 17-OHP, TSH and FT4. Contrast enhanced brain MRI showed a normal hypophysis without focal abnormalities in all patients.

Thirty-seven patients (Group 1) received a new diagnosis of CPP during and after the Italian lockdown and 12 (Group 2), already diagnosed with slow progression $\mathrm{CPP}$, presented an unexpected accelerated rate of pubertal progression in this period (Tables 1 and 2). The data of the new cases of CPP were compared with 89 patients with CPP diagnosed in the same period (March - July) of the years 2015-2019 (17.8 \pm 1.3 patients, range from 16 to 19 cases/same period/year). The data of the 12 patients with slow progressive CPP in whom pubertal progression accelerated were compared with 11 patients with the same characteristics who had been followed by our Unit in the previous 5 years $(2.2 \pm 0.4$ patients, ranging from 2 to 3 cases/same period/year).

Four patients were excluded from the study: two for CPP and cognitive delay (one of whom was adopted), one for a hypothalamic-pituitary malformation and one for puberty associated with Williams-Beuren syndrome.

The overall number of new CPP diagnoses was significantly higher during and after lockdown for COVID-19 than the mean number of cases for the same period each year from 2015 to 2019 ( $p<0.0005$, Table 1 and Fig. 1). The number of patients with slow progression CPP who transitioned to fast progression CPP during and after the lockdown was also significantly higher $(p<0.0005$, Table 2 and Fig. 2).

Compared with control group 1, the girls in group 1 of this study presented an earlier chronological age at B2 $(p<0.005)$, an earlier chronological age at diagnosis $(p<$ $0.0005)$, and a more advanced Tanner stage at diagnosis $(p<0.05)$. However, there was no significant difference between the time between the appearance of the B2 and diagnosis in group 1 patients and controls (respectively $3.1 \pm 0.9$ vs. $3.0 \pm 0.8$ months).

The patients in group 1 also had more markedly elevated basal LH and E2 levels and a higher LH peak after LHRH test in comparison with the control group $(p<0.005)$. They also presented greater increases in uterine length and ovarian volume $(p<0.0005)$. Auxological parameters such as height SDS, BMI SDS and bone age SDS were not 
Table 1 Clinical data and laboratory results in the patients of group 1 and controls

\begin{tabular}{|c|c|c|c|}
\hline Variable & Group 1 & Previous 5 years $^{\mathrm{a}}$ & $P$ \\
\hline Population number & 37 & 89 & - \\
\hline Chronological age at B2 (as referred by parents or family pediatrician) & $6.86 \pm 0.61$ & $7.22 \pm 0.48$ & $p<0.005$ \\
\hline Chronological age at diagnosis (yr) & $7.11 \pm 0.72$ & $7.53 \pm 0.50$ & $p<0.0005$ \\
\hline Time from B2 to diagnosis (months) & $3.1 \pm 0.9$ & $3.0 \pm 0.8$ & $P=\mathrm{NS}$ \\
\hline Height, SDS & $0.84 \pm 1.32$ & $0.79 \pm 1.44$ & $P=N S$ \\
\hline BMI, SDS & $0.83 \pm 0.91$ & $0.68 \pm 0.88$ & $P=\mathrm{NS}$ \\
\hline \multicolumn{4}{|l|}{ Tanner stage at diagnosis (percentage) } \\
\hline$\|$ & 43.8 & 55.5 & \\
\hline III & 53,1 & 38.8 & \multirow[t]{3}{*}{$p<0.05$} \\
\hline IV & 3.1 & 5.4 & \\
\hline V & - & - & \\
\hline Bone age (yr) & $9.40 \pm 1.10$ & $9.60 \pm 1.20$ & $p=\mathrm{NS}$ \\
\hline Bone age minus chronological age (yr) & $2.29 \pm 0.38$ & $2.07 \pm 0.70$ & $P=\mathrm{NS}$ \\
\hline Basal LH, IU/L & $1.2 \pm 0.7$ & $0.8 \pm 0.6$ & $p<0.005$ \\
\hline Basal FHS, IU/L & $1.9 \pm 1.7$ & $2.2 \pm 1.3$ & $p=\mathrm{NS}$ \\
\hline Peak LH at GnRH stimulation, IU/L & $11.9 \pm 4.2$ & $9.4 \pm 4.0$ & $p<0.005$ \\
\hline Basal estradiol (females only), pmol/L & $129.9 \pm 18.7$ & $117.6 \pm 19.2$ & $p<0.005$ \\
\hline Uterine length, $\mathrm{cm}$ & $4.42 \pm 0.43$ & $3.99 \pm 0.47$ & $p<0.0005$ \\
\hline Ovarian volume, $\mathrm{cm}^{3}$ & $3.32 \pm 0.42$ & $2.83 \pm 0.46$ & $p<0.0005$ \\
\hline Electronic device use (h) & $3.9 \pm 1.5$ & - & - \\
\hline
\end{tabular}

$\bar{a}=$ mean/yr. $B A$ bone age, $C A$ chronological age, $S D S$ standard deviation score, $B M I$ body mass index, $L H$ luteinizing hormone, FSH follicle-stimulating hormone, $G n R H$ gonadotropin releasing hormone test

Table 2 Clinical data and laboratory results of group 2 and controls (two evaluations after the same time of follow-up)

\begin{tabular}{|c|c|c|c|c|}
\hline \multirow[t]{2}{*}{ Variable } & \multicolumn{2}{|l|}{ Group 2} & \multicolumn{2}{|l|}{ Controls } \\
\hline & before lockdown & after lockdown & visit 1 & visit 2 \\
\hline Population number & 12 & 12 & 11 & 11 \\
\hline Chronological age at diagnosis (yr) & $7.47 \pm 0.53$ & - & $7.41 \pm 0.61$ & - \\
\hline Chronological age at follow-up (yr) & $7.95 \pm 0.49$ & $8.26 \pm 0.47$ & $7.93 \pm 0.51$ & $8.31 \pm 0.53$ \\
\hline Time between the two visits (yr) & - & $0.31 \pm 0.02$ & - & $0.38 \pm 0.02$ \\
\hline Height, SDS & $0.87 \pm 1.22$ & $0.89 \pm 1.25$ & $0.86 \pm 1.13$ & $0.90 \pm 1.16$ \\
\hline BMI, SDS & $0.61 \pm 0.85$ & $0.92 \pm 0.87$ & $0.60 \pm 0.93$ & $0.69 \pm 0.94$ \\
\hline$\Delta \mathrm{BMI}, \mathrm{SDS}$ & - & $0.32 \pm 0.02^{* * *}$ & - & $0.09 \pm 0.01^{* * *}$ \\
\hline \multicolumn{5}{|l|}{ Tanner stage, percentage } \\
\hline$\|$ & 47.6 & $-* * *$ & 63.6 & 54.5 \\
\hline III & 52.4 & $71.4^{* * *}$ & 36.4 & 45.5 \\
\hline IV & - & $28.6^{* * *}$ & - & - \\
\hline V & - & - & - & - \\
\hline Basal LH (IU/L) & $0.8 \pm 0.6^{*}$ & $1.4 \pm 0.6^{*}$ & $0.9 \pm 0.7$ & $1.1 \pm 0.7$ \\
\hline Basal FHS (IU/L) & $1.9 \pm 1.5$ & $1.5 \pm 1.3$ & $1.6 \pm 1.4$ & $1.5 \pm 1.2$ \\
\hline Peak LH at GnRH stimulation (IU/L) & $9.6 \pm 3.4^{*}$ & $12.5 \pm 3.1^{*}$ & $9.0 \pm 3.1$ & $11.7 \pm 3.3$ \\
\hline Basal estradiol (females only) & $111.3 \pm 15.2^{* *}$ & $133.4 \pm 18.3^{* *}$ & $113.8 \pm 13.9$ & $119.1 \pm 15.4$ \\
\hline Uterine length, $\mathrm{cm}$ & $4.10 \pm 0.49^{*}$ & $4.59 \pm 0.47^{*}$ & $4.00 \pm 0.35$ & $4.35 \pm 0.37$ \\
\hline Ovarian volume, $\mathrm{cm}^{3}$ & $2.94 \pm 0.52^{*}$ & $3.43 \pm 0.48^{*}$ & $2.86 \pm 0.46$ & $3.18 \pm 0.46$ \\
\hline Electronic device use (h) & $1.6 \pm 0.9^{* * *}$ & $3.9 \pm 1.5^{* * *}$ & - & - \\
\hline
\end{tabular}

${ }^{*}=p<0.05 ;{ }^{* *} P=0.005 ;{ }^{* * *}=p<0.0005$. BA bone age, $C A$ chronological age, SDS standard deviation score, $B M I$ body mass index, $L H$ luteinizing hormone, FSH follicle-stimulating hormone, GnRH gonadotropin releasing hormone test 


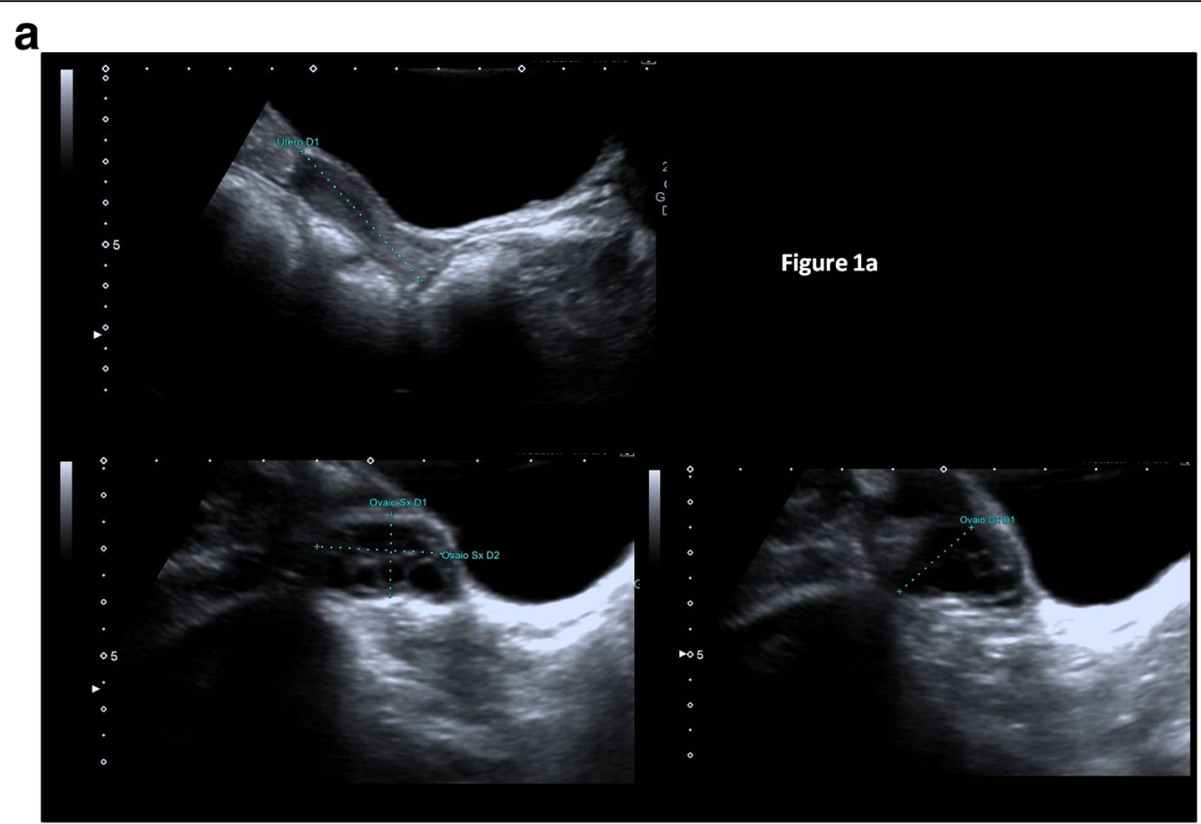

b

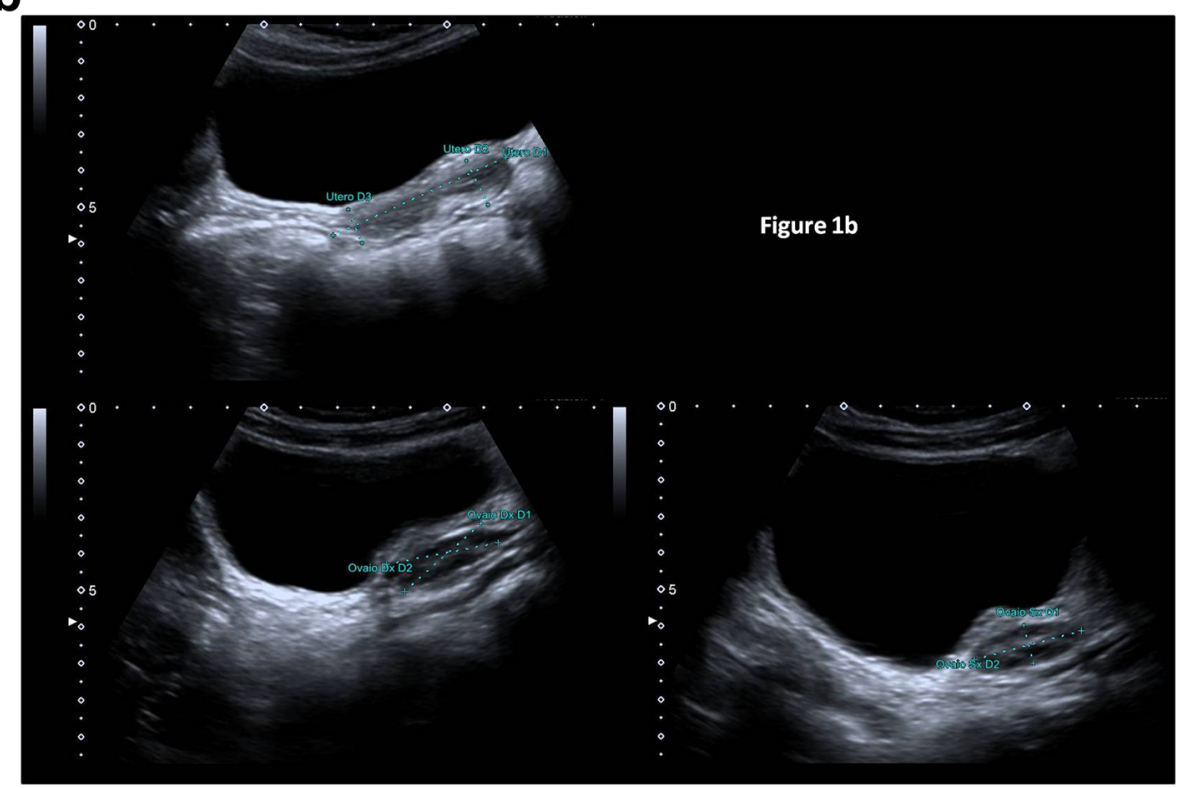

Fig. 1 Two girls with precocious puberty diagnosed during lockdown for COVID-19. Patient 1 started puberty at 6.2 years (March 2020): May 2020: height 1.45 SDS, BMI 0.45 SDS; Tanner stage B3 PH2 AH1); patient's pelvic sonography (May 2020; a). Patient 2 started puberty at 6.9 years (February 2020): May 2020: height 1.36 SDS, BMI 0.52 SDS; Tanner stage B3 PH1 AH1); patient's pelvic sonography (May 2020; b)

statistically different between group 1 patients and controls, but BMI SDS increased significantly in group 1 during the lockdown $(p<0.05)$.

Compared with the previous 5 years, during lockdown, the number of patients with CCP who experienced a transition from slowly progressive pubertal development to accelerated pubertal development was statistically significant $(p<0.0005)$. Compared with controls, patients in group 2 at the same stage in follow-up $(0.31 \pm 0.02 \mathrm{vs}$. $0.38 \pm 0.02$ years $)$, had significantly elevated LH $(p<0.05)$ and E2 levels $(p<0.005)$, as well as a higher LH peak after LHRH test $(p<0.05)$ and a significantly accelerated progression rate as measured by the Tanner scale $(p<$ $0.0005)$, uterine length $(p<0.05)$, and ovarian volume $(p<0.05)$. As in group 1 , for patients in group 2 , auxological parameters (height SDS, bone age SDS) were not statistically different from controls but $\triangle$ BMI SDS increased significantly $(p<0.005)$.

The evaluation of the use of electronic devices before and during the lockdown in the two groups, showed a 


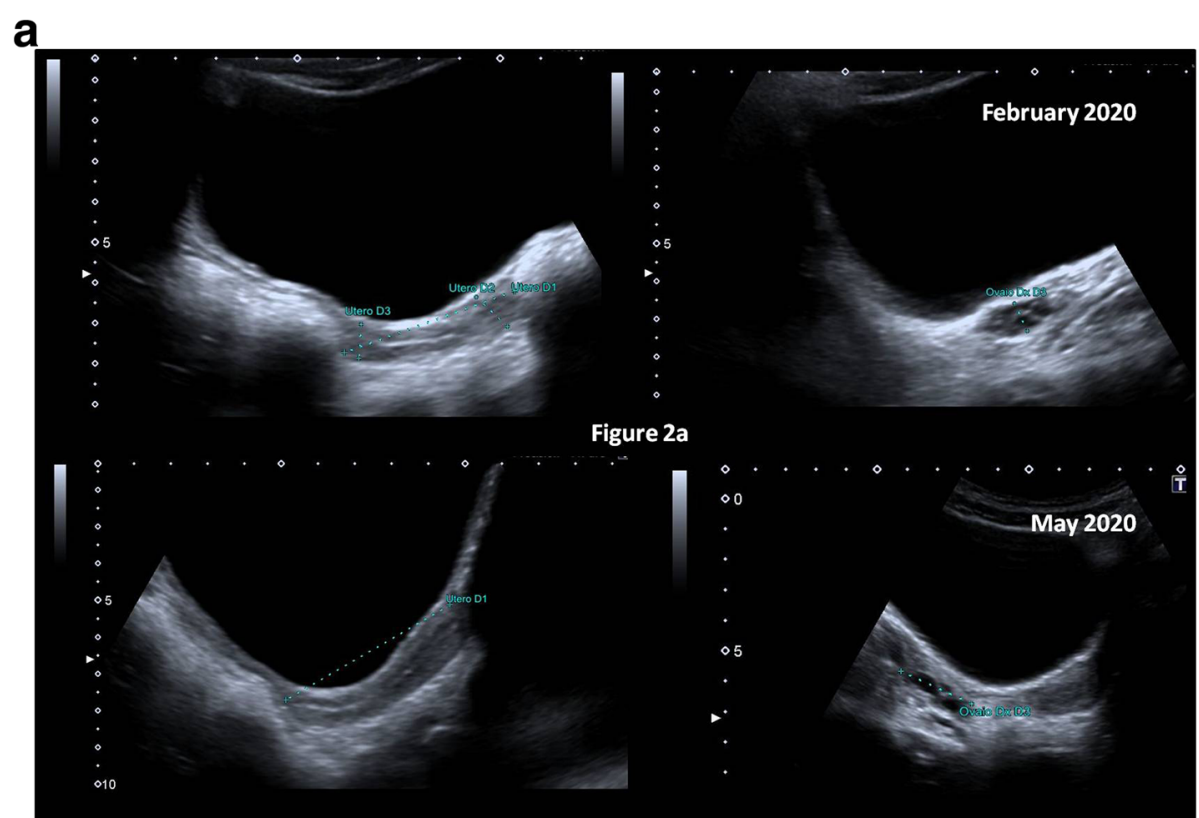

b

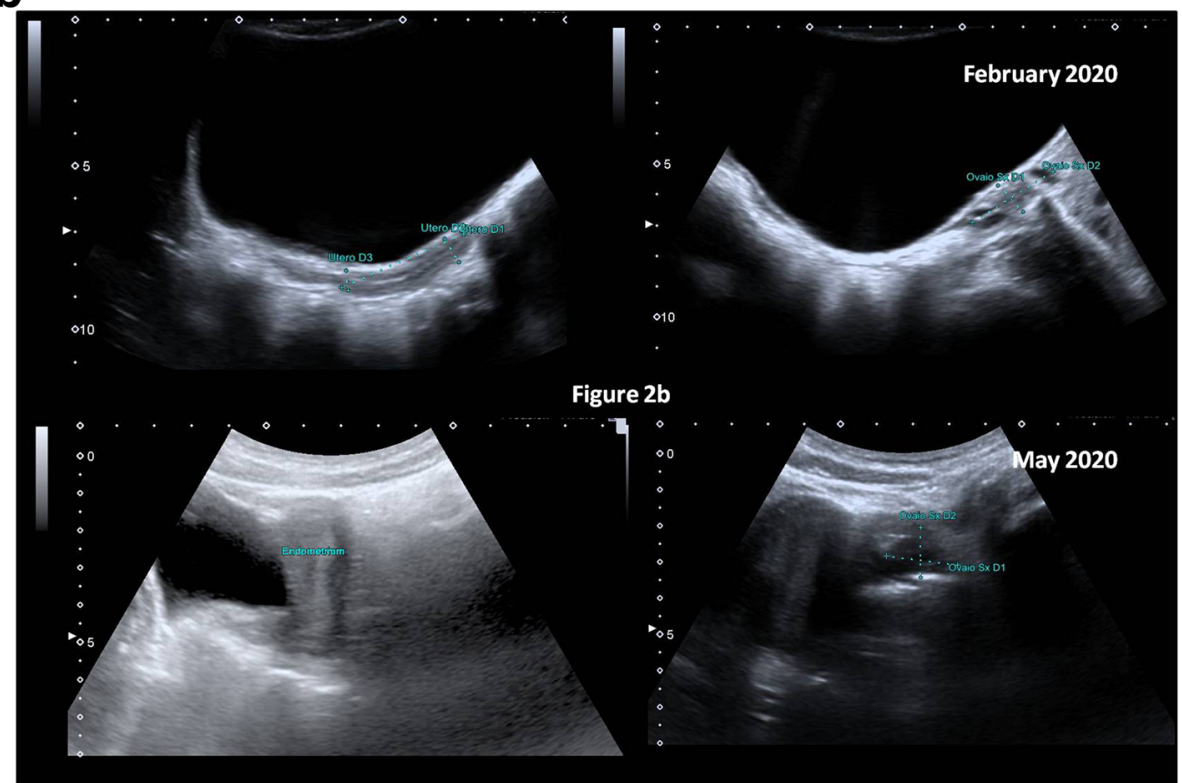

Fig. 2 Two girls with central precocious puberty with a slow rate progression before lockdown and acceleration during or after lockdown for COVID-19. Patient 1 started puberty at 7.5 years (November 2019: height 1.23 SDS, BMI 0.88 SDS; Tanner stage B2 PH1 AH1); the second pelvic sonography, February 2020 (a) is similar to the sonography at diagnosis (uterine length $43 \mathrm{~mm}$ and ovary volumes respectively 1.8 and $1.2 \mathrm{~mL}$ ); the sonography in May 2020 (b) showing an acceleration in the tempo of puberty (height 1.29 SDS, BMI 0.91 SDS; Tanner stage B3-4 PH2 AH1; uterine length $52 \mathrm{~mm}$, ovaries volume 4,9 and 4,0 mL). Patient 2 started puberty at 7.4 years (October 2019: height 1.17 SDS, BMI 0.69 SDS; Tanner stage B2 PH1 AH1); the second pelvic sonography in February 2020 (b) is similar to the sonography at diagnosis (uterine length $45 \mathrm{~mm}$ and ovaries volume respectively 3.8 and $3.7 \mathrm{~mL}$ ); the sonography in May 2020 shows also an acceleration in the tempo of puberty (height 1.22 SDS, BMI 0.76 SDS; Tanner stage B3-4 PH1 AH1; uterine length $63 \mathrm{~mm}$ and ovary volumes respectively 6.4 and $8.8 \mathrm{~mL}$ )

significantly increased use (before: $1.6 \pm 0.9 \mathrm{~h}$ /day; during: $3.9 \pm 1.5 \mathrm{~h} /$ day, $p<0.0005)$. The main use was for school lessons and study $(1.8 \pm 0.8 \mathrm{~h} /$ day $)$, but also for entertainment
(TV and videogames) $(1.3 \pm 0.8 \mathrm{~h} /$ day vs. $0.7 \pm 0.5 \mathrm{~h} /$ day, $p<0.0005)$. Use of devices during the hours before sleeping also significantly increased $(p<0.0005)$. 


\section{Discussion}

Our study shows a significantly increased incidence of new diagnoses of central precocious puberty and a faster rate of pubertal progression in previously diagnosed patients during and after the lockdown for COVID-19 in comparison with the same period of the 5 previous years. Our results seem to suggest a correlation between environmental factors and early onset and fast progression puberty. Our study focuses on female patients, but we hypothesize that such factors may also affect pubertal development in boys. As diagnosis in males is more frequent at the G2 stage of genital development, it would be interesting to evaluate any increases in the frequency of CPP in male patients over the coming months.

In humans, $70-80 \%$ of variances in pubertal timing and tempo can be explained by genetic factors, but the role of environmental factors is also well known [2, 5]. A number of studies, reported an earlier menarcheal age in girls with a low birth weight or in utero growth retardation, showing that the possible effects of the environment start during intrauterine life [26], although other studies contradict this conclusion [27].

Our study may help shed light on 3 factors hypothesized in the literature as potentially contributing to the timing and/or tempo of pubertal development: an increased BMI [28, 29], the "overuse" of electronic devices [21] and psychological triggers [30].

Nutrition plays a key role in the timing of puberty and could explain, at least partially, the secular trend of earlier development [31]. Obesity is associated with early menarcheal age [29, 32]. Leptin, insulin-like growth factor-I and glucose have been shown to be involved in the control of $\mathrm{GnRH}$ secretion, but their role in the timing of puberty remains controversial [31]. The effects of fat mass may also interact with the effect of some endocrine disrupters that have a high affinity for lipids and are stored in fat tissue, thus creating conditions for the persistence of systemic effects [31].

Psychological factors may also be important. It is likely that the COVID-19 pandemic impacted the mental health and well-being of children considerably. Illness, anxiety about becoming ill as well as prolonged social distancing may have lasting effects on children [33]. The closure of schools, the sudden disruption of extended social and family relationships, the change in daily habits and parental anxiety about financial and other problems may have affected children's emotional stability and sense of security [33]. As yet there is little data on how children in all countries responded psychologically to the crisis but [34] the importance of psychological factors in precocious puberty has been reported in children migrating from developing to developed countries, primarily through international adoption [35]. It has been hypothesised that for adopted children who move from a deprived environment to a resource rich environment, environmental factors which slow or delay pubertal development are deactivated while factors which favour pubertal development are enhanced, triggering the onset of puberty [35]. Genetic factors cannot fully explain the high incidence of precocious puberty in internationally adopted girls as their average menarcheal age is lower than the average menarcheal age both in their foster countries and in their countries of origin [35].

Our data show an increased use of electronic devices; the time spent by the children on electronic devices increased by a factor of 2.5 during lockdown. We may hypothesize that the overuse of electronic devices contributes to the timing and/or tempo of puberty. A number of studies have recently investigated the effects of exposure to electromagnetic fields on melatonin [21, 36-38]. Exposure to simulated electromagnetic fields has been associated with decreased melatonin production by isolated pinealectocytes in vitro, as well as with a decreased pineal and plasma melatonin and its urinary metabolites [36]. The study in the town of Cavriglia showed an overall and age-dependent decrease in urinary melatonin concentration associated with children's exposure to a television screen which was more pronounced in younger children [21]. Night-time serum melatonin levels are highest in very young children and drop progressively by $80 \%$ throughout childhood until adolescence and young adulthood [39]. There is some evidence that the drop in nocturnal melatonin levels parallels sexual maturation processes [40], as measured by the Tanner scale [41]. Animal studies also show that a reduction in melatonin may accelerate pubertal development [42] and that exogenous melatonin can suppress $\mathrm{GnRH}$ secretion [43]. It is plausible that a greater use of electronic devices leads to a reduction in melatonin levels which in turn triggers the endocrine changes that lead to the onset of pubertal development at an earlier age [44].

We are aware that this study has several limitations, including its small sample size. The COVID-19 pandemic caused profound and sudden changes in community care and hospital settings, making it impossible to create a homogeneous control group. We underline the need for more studies involving larger numbers of CPP patients. Moreover, our study did not assess decreases the changes in physical activity or in calorie intake in these children. However, increases in calorie intake and decreases in physical activity have been observed in the Italian population during lockdown [13] and it is likely that also our children were affected in a similar way.

\section{Conclusion}

In conclusion, our data shows an increase in the incidence of new CPP diagnoses, as well as a faster rate of 
pubertal progression in previously diagnosed patients, during and after lockdown for COVID-19, suggesting that environmental factors, such as the BMI and the use of electronic devices, which emerged during the lockdown played a triggering role. Further studies are needed to confirm our data and elucidate the relative importance of the various factors at play and how they interact. In this uncertain period, clinicians should be aware of the signs of pubertal developmental disorders and should carefully monitor existing patients with CPP for signs of accelerated pubertal progression.

\section{Acknowledgements}

Thanks to Tammy Ann Corkish BA MA for advice on the use of clear English.

Studies involving animals must include a statement on ethics approval Not applicable.

\section{Authors' contributions}

All authors participated in the drafting of the manuscript unanimously. All authors read and approved the final manuscript.

\section{Funding}

No external funding was provided for this study.

\section{Availability of data and materials}

Yes.

\section{Ethics approval and consent to participate}

The study was performed according to the Helsinki II declaration and approved by the local Paediatric Ethical Committee (approval number: 30/ 07/2020-179). Written informed consent was obtained from the parents of enrolled children.

\section{Consent for publication}

Written informed consent was obtained from the parents of enrolled children.

\section{Competing interests}

The authors have no conflicts of interest to declare.

\section{Author details}

'Health Sciences Department, Anna Meyer Children's University Hospital, University of Florence, Viale Pieraccini 24, 50139 Florence, Italy. ${ }^{2}$ Anna Meyer Children's University Hospital, Viale Pieraccini 24, 50139, Florence, Italy.

\section{Received: 8 September 2020 Accepted: 26 October 2020}

\section{Published online: 04 November 2020}

\section{References}

1. Parent AS, Rasier G, Gerard A, Heger S, Roth C, Mastronardi C, et al. Early onset of puberty: tracking genetic and environmental factors. Horm Res. 2005;64(Suppl 2):41-7. https://doi.org/10.1159/000087753.

2. Parent AS, Teilmann G, Juul A, Skakkebaek NE, Toppari J, Bourguignon JP. The timing of normal puberty and the age limits of sexual precocity: variations around the world, secular trends, and changes after migration. Endocr Rev. 2003;24(5):668-93. https://doi.org/10.1210/er.2002-0019.

3. Herman-Giddens ME, Slora EJ, Wasserman RC, Bourdony CJ, Bhapkar MV, Koch GG, Hasemeier CM. Secondary sexual characteristics and menses in young girls seen in office practice: a study from the pediatric research in office settings network. Pediatrics. 1997;99(4):505-12. https://doi.org/10. 1542/peds.99.4.505.

4. Lee PA, Guo SS, Kulin HE. Age of puberty: data from the United States of America. APMIS. 2001;109(2):81-8. https://doi.org/10.1034/j.1600-0463.2001.d01-107.x.

5. Sørensen K, Mouritsen A, Aksglaede L, Hagen CP, Mogensen SS, Juul A. Recent secular trends in pubertal timing: implications for evaluation and diagnosis of precocious puberty. Horm Res Paediatr. 2012;77(3):137-45. https://doi.org/10.1159/000336325.
6. Euling SY, Herman-Giddens ME, Lee PA, Selevan SG, Juul A, Sørensen TI, et al. Examination of US puberty-timing data from 1940 to 1994 for secular trends: panel findings. Pediatrics. 2008;121(Suppl 3):S172-91. https://doi.org/ 10.1542/peds.2007-1813D.

7. Biro FM, Galvez MP, Greenspan LC, Succop PA, Vangeepuram N, Pinney SM, et al. Pubertal assessment method and baseline characteristics in a mixed longitudinal study of girls. Pediatrics. 2010;126:e583-90.

8. Elks CE, Perry JR, Sulem P, Chasman DI, Franceschini N, He C, et al. Thirty new loci for age at menarche identified by a meta-analysis of genome-wide association studies. Nat Genet. 2010:42(12):1077-85. https://doi.org/10.1038/ng.714.

9. Zhang L, Zhang D, Sun Y. Adverse childhood experiences and early pubertal timing among girls: a meta-analysis. Int J Environ Res Public Health. 2019;16(16):2887. https://doi.org/10.3390/ijerph16162887.

10. Baqui P, Bica I, Marra V, Ercole A, van der Schaar M. Ethnic and regional variations in hospital mortality from COVID-19 in Brazil: a cross-sectional observational study. Lancet Glob Health. 2020;8(8):e1018-26. https://doi.org/ 10.1016/S2214-109X(20)30285-0.

11. Dvorsky MR, Breaux R, Becker SP. Finding ordinary magic in extraordinary times: child and adolescent resilience during the COVID-19 pandemic. Eur Child Adolesc Psychiatry. 2020:1-3. https:/doi.org/10.1007/s00787-020-01583-8.

12. Dave H, Yagnik P. Psycho-social impact of COVID-19 pandemic on children in India: the reality. Child Abuse Negl. 2020;108:104663. https://doi.org/10. 1016/j.chiabu.2020.104663.

13. Pietrobelli A, Pecoraro L, Ferruzzi A, Heo M, Faith M, Zoller T, et al. Effects of COVID-19 lockdown on lifestyle behaviors in children with obesity living in Verona, Italy: a longitudinal study. Obesity (Silver Spring). 2020;28(8):1382-5. https://doi.org/10.1002/oby.22861.

14. Karatzias T, Shevlin M, Murphy J, McBride O, Ben-Ezra M, Bentall RP, et al. Posttraumatic Stress Symptoms and Associated Comorbidity During the COVID-19 Pandemic in Ireland: A Population-Based Study. J Trauma Stress. 2020. https://doi.org/10.1002/jts.22565.

15. Stagi S, Galli L, Cecchi C, Chiappini E, Losi S, Gattinara CG, et al. Final height in patients perinatally infected with the human immunodeficiency virus. Horm Res Paediatr. 2010;74(3):165-71. https://doi.org/10.1159/000281018.

16. Stagi S, Ricci F, Bianconi M, Sammarco MA, Municchi G, Toni S, et al. Retrospective evaluation of metformin and/or metformin plus a new polysaccharide complex in treating severe Hyperinsulinism and insulin resistance in obese children and adolescents with metabolic syndrome. Nutrients. 2017;9(5):524. https://doi.org/10.3390/nu9050524.

17. Marshall WA, Tanner JM. Variations in patterns of pubertal changes in girls. Arch Dis Child. 1969;44(235):291-303. https://doi.org/10.1136/adc.44.235.291.

18. Carel JC, Eugster EA, Rogol A, Ghizzoni L, Palmert MR. ESPE-LWPES GnRH analogs consensus conference group, et al. consensus statement on the use of gonadotropin-releasing hormone analogs in children. Pediatrics. 2009;123(4):e752-62. https://doi.org/10.1542/peds.2008-1783.

19. Lanes R, Soros A, Jakubowicz $S$. Accelerated versus slowly progressive forms of puberty in girls with precocious and early puberty. Gonadotropin suppressive effect and final height obtained with two different analogs. J Pediatr Endocrinol Metab. 2004;17(5):759-66. https://doi.org/10.1515/jpem.2004.17.5.759.

20. Brito VN, Spinola-Castro AM, Kochi C, Kopacek C, Silva PC, Guerra-Júnior G. Central precocious puberty: revisiting the diagnosis and therapeutic management. Arch Endocrinol Metab. 2016;60(2):163-72. https://doi.org/ 10.1590/2359-3997000000144

21. Salti R, Tarquini R, Stagi S, Perfetto F, Cornélissen G, Laffi G, et al. Agedependent association of exposure to television screen with children's urinary melatonin excretion? Neuro Endocrinol Lett. 2006;27(1-2):73-80.

22. Hysing M, Pallesen S, Stormark KM, Jakobsen R, Lundervold AJ, Sivertsen B. Sleep and use of electronic devices in adolescence: results from a large population-based study. BMJ Open. 2015;5(1):e006748. https://doi.org/10. 1136/bmjopen-2014-006748

23. Greulich WW, Pyle SI. Radiographic atlas of skeletal development of the hand and wrist. Stanford: Stanford University Press; 1959.

24. Hermanussen $\mathrm{M}$, Cole J. The calculation of target height reconsidered. Horm Res. 2003:59(4):180-3.

25. Massin N, Gougeon A, Meduri G, Thibaud E, Laborde K, Matuchansky C, et al. Significance of ovarian histology in the management of patients presenting a premature ovarian failure. Hum Reprod. 2004;19(11):2555-60.

26. Gavela-Pérez T, Garcés C, Navarro-Sánchez P, López Villanueva L, SorianoGuillén L. Earlier menarcheal age in Spanish girls is related with an increase in body mass index between pre-pubertal school age and adolescence. Pediatr Obes. 2015;10(6):410-5. https://doi.org/10.1111/ijpo.277. 
27. Mishra GD, Cooper R, Tom SE, Kuh D. Early life circumstances and their impact on menarche and menopause. Womens Health (Lond). 2009;5(2): 175-90. https://doi.org/10.2217/17455057.5.2.175.

28. Brix N, Ernst A, Lauridsen LLB, Parner ET, Arah OA, Olsen J, et al. Childhood overweight and obesity and timing of puberty in boys and girls: cohort and sibling-matched analyses. Int J Epidemiol. 2020;49(3):834-44. https://doi.org/ 10.1093/ije/dyaa056

29. Rubin C, Maisonet M, Kieszak S, Monteilh C, Holmes A, Flanders D, et al. Timing of maturation and predictors of menarche in girls enrolled in a contemporary British cohort. Paediatr Perinat Epidemiol. 2009;23(5):492-504. https://doi.org/10.1111/j.1365-3016.2009.01055.x.

30. Wierson M, Long PJ, Forehand RL. Toward a new understanding of early menarche: the role of environmental stress in pubertal timing. Adolescence. 1993;28(112):913-24.

31. Karpati AM, Rubin CH, Kieszak SM, Marcus M, Troiano RP. Stature and pubertal stage assessment in American boys: the 1988-1994 third National Health and nutrition examination survey. J Adolesc Health. 2002;30(3):20512. https://doi.org/10.1016/s1054-139x(01)00320-2.

32. Juul A, Teilmann G, Scheike T, Hertel NT, Holm K, Laursen EM, et al. Pubertal development in Danish children: comparison of recent European and US data. Int J Androl. 2006;29(1):247-55. https://doi.org/10.1111/j.1365-2605.2005.00556.X.

33. Xie X, Xue Q, Zhou Y, Zhu K, Liu Q, Zhang J, Song R. Mental health status among children in home confinement during the coronavirus disease 2019 outbreak in Hubei Province, China. JAMA Pediatr. 2020:e201619. https://doi. org/10.1001/jamapediatrics.2020.1619.

34. Zhou SJ, Zhang LG, Wang LL, Guo ZC, Wang JQ, Chen JC, Chen JX. Prevalence and socio-demographic correlates of psychological health problems in Chinese adolescents during the outbreak of COVID-19. Eur Child Adolesc Psychiatry. 2020;29(6):749-58. https://doi.org/10.1007/s00787-020-01541-4.

35. Stagi S, Papacciuoli V, Boiro D, Maggioli C, Ndambao NN, Losi S, et al. Auxological and endocrinological features in internationally adopted children. Ital J Pediatr. 2020;46(1):82. https://doi.org/10.1186/s13052-020-00832-5.

36. Sangün Ö, Dündar B, Çömlekçi S, Büyükgebiz A. The effects of electromagnetic field on the endocrine system in children and adolescents. Pediatr Endocrinol Rev. 2015;13(2):531-45.

37. Akkaya R, Gümüş E, Akkaya B, Karabulut S, Gülmez K, Karademir M, et al. Wi-fi decreases melatonin protective effect and increases hippocampal neuronal damage in pentylenetetrazole induced model seizures in rats. Pathophysiology. 2019:26(3-4):375-9. https://doi.org/10.1016/.jpathophys.2019.11.003.

38. Lewczuk B, Redlarski G, Zak A, Ziółkowska N, Przybylska-Gornowicz B, Krawczuk M. Influence of electric, magnetic, and electromagnetic fields on the circadian system: current stage of knowledge. Biomed Res Int. 2014; 2014:169459. https://doi.org/10.1155/2014/169459.

39. Waldhauser F, Weiszenbacher G, Tatzer E, Gisinger B, Waldhauser M, Schemper M, Frisch H. Alterations in nocturnal serum melatonin levels in humans with growth and aging. J Clin Endocrinol Metab. 1988;66(3):648-52. https://doi.org/10.1210/jcem-66-3-648.

40. Waldhauser F, Waldhauser M, Lieberman HR, Deng MH, Lynch HJ, Wurtman RJ. Bioavailability of oral melatonin in humans. Neuroendocrinology. 1984; 39(4):307-13. https://doi.org/10.1159/000123997.

41. Waldhauser F, Weiszenbacher G, Frisch H, Zeithuber U, Waldhauser M, Wurtman RJ. Fall in nocturnal serum melatonin during prepuberty and pubescence. Lancet. 1984;1(8373):362-5. https://doi.org/10.1016/s01406736(84)90412-4.

42. Hadinia SH, Carneiro PRO, Fitzsimmons CJ, Bédécarrats GY, Zuidhof MJ. Post-photostimulation energy intake accelerated pubertal development in broiler breeder pullets. Poult Sci. 2020;99(4):2215-29. https://doi.org/10. 1016/j.psj.2019.11.065.

43. Roy D, Belsham DD. Melatonin receptor activation regulates GnRH gene expression and secretion in GT1-7 GnRH neurons. Signal transduction mechanisms. J Biol Chem. 2002;277(1):251-8. https://doi.org/10.1074/jbc. M108890200

44. Boafo A, Greenham S, Alenezi S, Robillard R, Pajer K, Tavakoli P, De Koninck. J. Could long-term administration of melatonin to prepubertal children affect timing of puberty? A clinician's perspective. Nat Sci Sleep. 2019;11:110. https://doi.org/10.2147/NSS.S181365.

\section{Publisher's Note}

Springer Nature remains neutral with regard to jurisdictional claims in published maps and institutional affiliations.

\section{Ready to submit your research? Choose BMC and benefit from:}

- fast, convenient online submission

- thorough peer review by experienced researchers in your field

- rapid publication on acceptance

- support for research data, including large and complex data types

- gold Open Access which fosters wider collaboration and increased citations

- maximum visibility for your research: over $100 \mathrm{M}$ website views per year

At $\mathrm{BMC}$, research is always in progress.

Learn more biomedcentral.com/submissions 